\title{
Soluble Highly Heat Resistant Aromatic Polyimides
}

\author{
Yuki Shirai ${ }^{a}$, Takehiro Kawauchi ${ }^{a}$, Tsutomu Takeichi ${ }^{\mathrm{a} *}$ and Hiroshi Itatani ${ }^{\mathrm{b}}$ \\ ${ }^{a}$ Department of Environmental and Life Sciences, Toyohashi University of Technology, \\ Tempaku-cho, Toyohashi 441-8580, JAPAN \\ ${ }^{b}$ Solpit Industries, LTD., D-28, 2-1-6, Sengen, Tsukubashi, 305-0047, Japan \\ takeichi@ens.tut.ac.jp
}

Keywords: soluble polyimide, heat resistant, aromatic polyimide

\section{Introduction}

Polyimide (PI) is one of the most important super-engineering plastics because of their superior properties, such as excellent thermal and mechanical properties, low dielectric constant and chemical resistance. PI also has excellent molecular design flexibility because of the wide variation of monomers available. Now, PI is extensively used as electronic materials including interlayer insulation films, buffer coating films, alpha-ray shielding films, and alignment films for liquid crystal displays [1-3]. The representative PI is Kapton-H, which is made from pyromellitic dianhydride (PMDA) and 4,4'-diaminodiphenyl ether (DADE) [4]. Itatani synthesized biphenyltetracarboxylic dianhydride (BPDA), and used BPDA for the synthesis of Upilex. These PIs are highly heat resistant, but hardly soluble in organic solvents. Therefore, these PIs are processed into thin films at the stage of poly(amide acid) (PAA), followed by imidization. This process has some disadvantages such as long time needed to make films and instability of PAA due to the hydrolysis by moisture. These problems can be solved by using soluble PI.

Generally, soluble PIs can be synthesized by selecting special type of monomers, which are relatively expensive. Thermal properties of these soluble PIs are often low. In the preparation of soluble PI, addition of acid catalyst such as phosphoric acid and toluenesulfonic acid is effective to obtain high molecular weight polyimide. However, the catalyst remains in the PI film and cause degradation. Itatani developed new catalyst system, which become active by water (Scheme 1). The catalyst can be evaporated by heat tereatment, along with water by adding azeotropic solvent such as toluene [5].

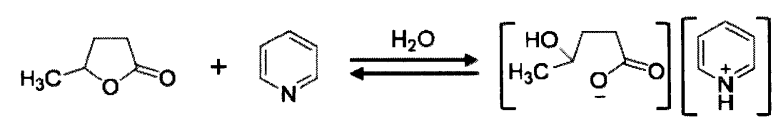

Scheme 1. Catalytic effect of $\gamma$-valerolactone/ pyridine.

In this paper, we prepared highly heat resistant and soluble aromatic polyimides using PMDA and BPDA, which are usually difficult to prepare soluble PI. For that purpose, we used new three step reactions to precisely control the polyimide sequence as shown in Scheme 2. The PI composition in this study is [(PMDA $)_{4}(\mathrm{DADE})_{2}$ $\left.(\mathrm{BPDA})_{2}(\mathrm{DAT})_{4}\right]_{\mathrm{n}}$, and was named $6,6-\mathrm{PI}$. Various PIs can be obtained by changing the structure of monomers, especially the diamine at the third step.

\section{Experimental}

2.1. Reagents

PMDA, DADE, and 2,4-diaminotoluene (DAT) were obtained from Tokyo Kasei Kogyo (Tokyo, Japan). 3,3',4,4'-Biphenyltetracarboxylic dianhydride (BPDA) was purchased from UBE Industries (Tokyo, Japan). $\gamma$-Valerolactone, pyridine, 1-methyl-2-pyrrolidinone (NMP), and toluene were obtained from Wako Chemical (Osaka, Japan).

\subsection{Preparation of Polyimide}

Soluble PI, 6,6-PI, was prepared from PMDA, BPDA, DADE, and DAT as follows. Into a $500 \mathrm{ml}$ separable flask equipped with nitrogen inlet and mechanical stirrer, DADE $(4.00 \mathrm{~g}, 20 \mathrm{mmol})$ and $60.0 \mathrm{~g}$ of NMP were added. The mixture was kept stirring until clear solution was obtained. BPDA $(2.94 \mathrm{~g}, 10 \mathrm{mmol})$ was added to the solution and the 
First step

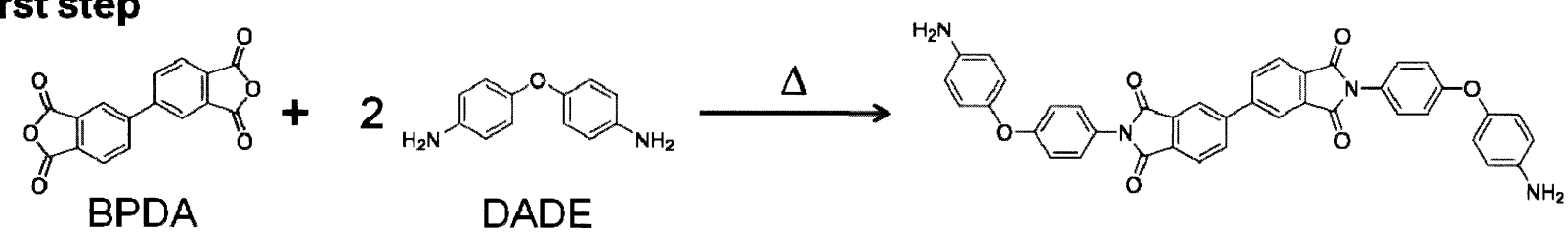

\section{Second step}

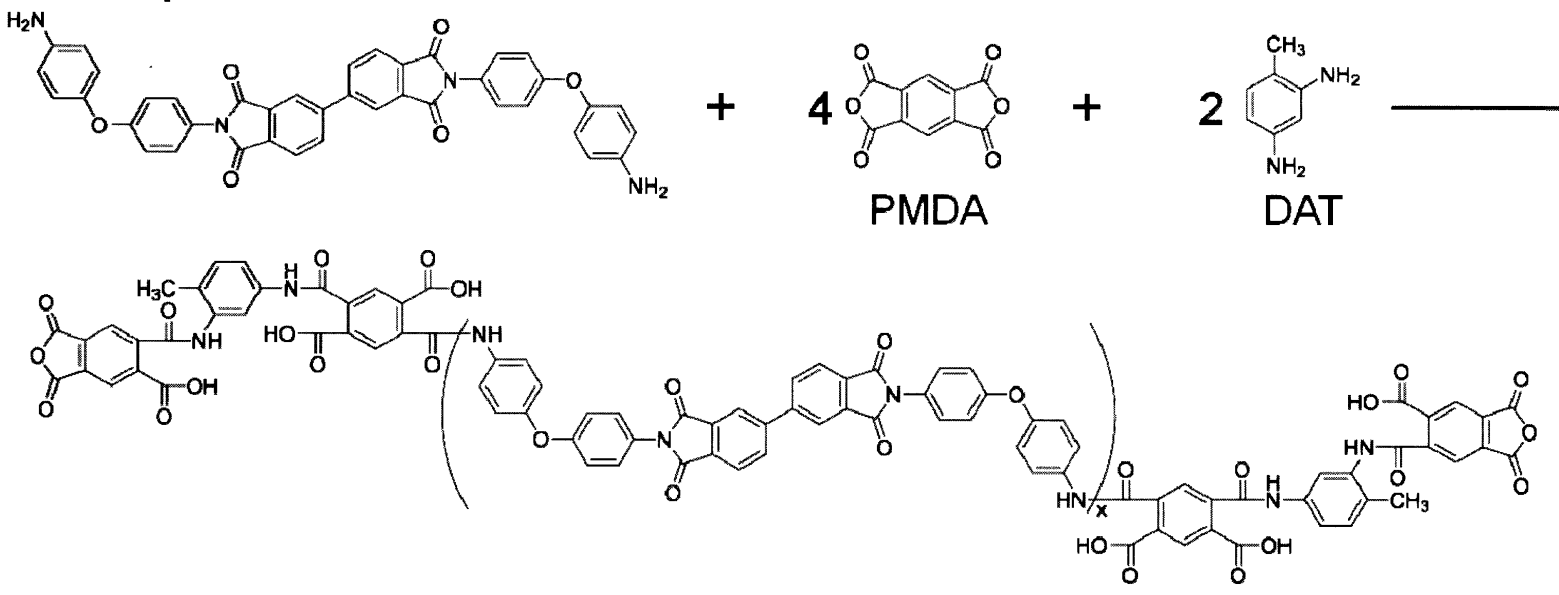

\section{Third step}
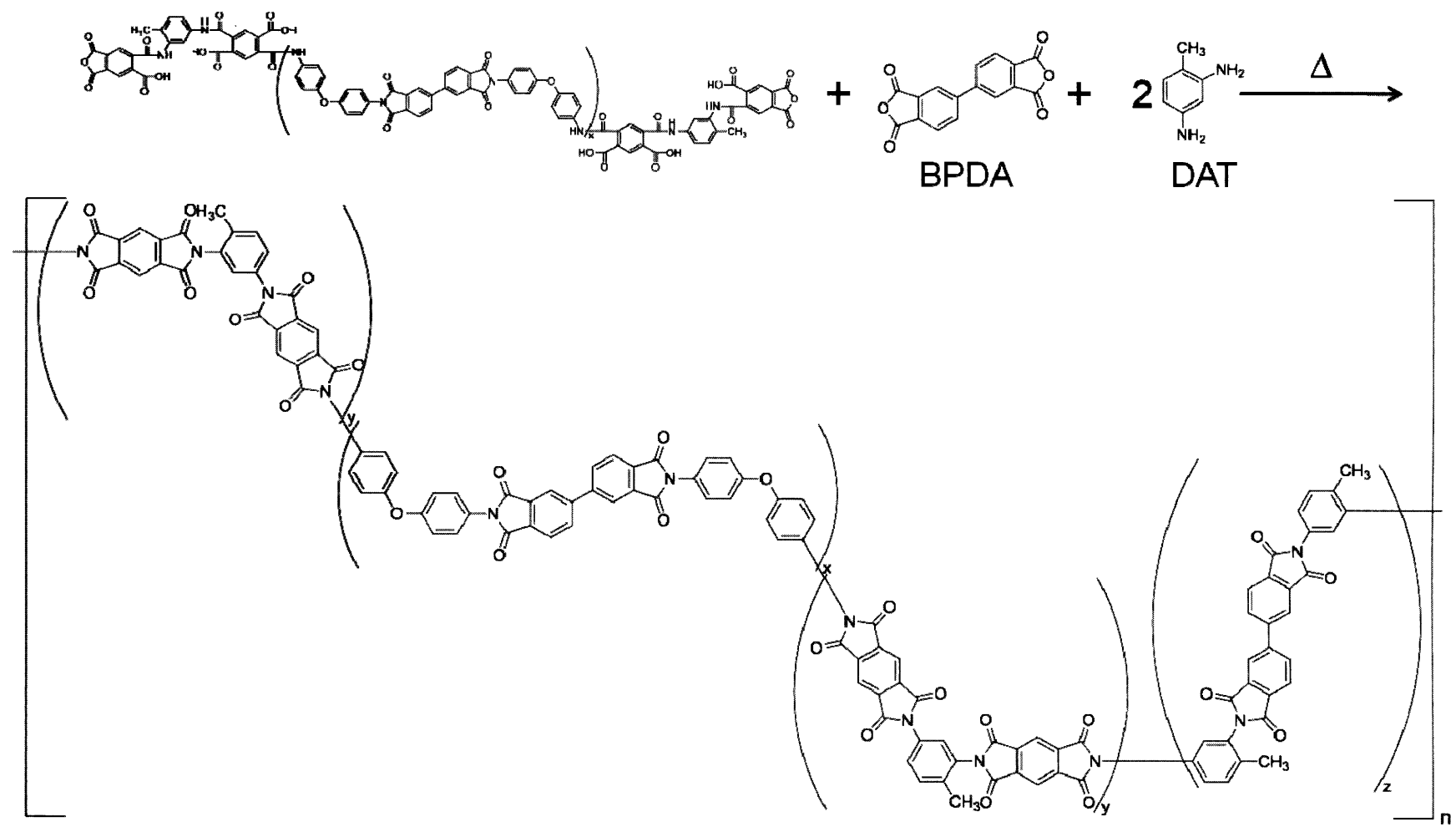

6,6- PI

Scheme 2. Synthesis of 6,6-PI. 
wall of the flask was washed with a mixture of toluene $(20 \mathrm{~g})$ and NMP $(20 \mathrm{~g})$ containing pyridine $(2.0 \mathrm{mmol})$ and $\gamma$-valerolactone $(2.0 \mathrm{mmol})$. The reaction mixture was stirred for $1 \mathrm{~h}$ at $180^{\circ} \mathrm{C}$ to give a transparent dark red imide oligomer solution. After cooling down to room temperature, PMDA (40 $\mathrm{mmol})$, DAT $(20 \mathrm{mmol})$ and $80.0 \mathrm{~g}$ of NMP were added, and stirred for 30 minutes at room temperature. Finally, BPDA (10 mmol), DAT (20 $\mathrm{mmol}$ ), and $74.8 \mathrm{~g}$ of NMP were added, and stirred for $3 \mathrm{~h}$ at $180{ }^{\circ} \mathrm{C}$ to give a transparent dark brown 6,6-PI solution.

For comparison, Kapton-H type PAA was prepared from PMDA and DADE. PAA(PMDA/DADE) was cast on a glass plate, cured in air oven at $150{ }^{\circ} \mathrm{C}$ and $300{ }^{\circ} \mathrm{C}$ for $1 \mathrm{~h}$, respectively.

\subsection{Measurements}

IR spectra were obtained using a Jasco Fourier Transform IR-420 spectrophotometer. Molecular weights were measured by a gel permeation chromatography (GPC) in NMP using a Tosoh HLC-8320 GPC system and polystyrene standards for calibration. Thermogravimetric analysis (TGA) was performed with a Rigaku Thermo Plus TG8120 at a heating rate of $5{ }^{\circ} \mathrm{C} / \mathrm{min}$ under argon. Tensile properties were recorded with Imada Seisaku-sho Model SV-3 at a crosshead speed of $1 \mathrm{~mm} / \mathrm{min}$ using films of $2 \mathrm{~cm}$ long. The tensile properties of each sample were determined from an average of at least 10 tests. Dynamic mechanical analysis (DMA) was conducted on a Seiko Instruments model EXSTAR DMS6100 at $1 \mathrm{~Hz}$ at a heating rate of $5^{\circ} \mathrm{C} / \mathrm{min}$.

\section{Results and Discussion}

\subsection{Characterization}

Number average molecular weight $(M \mathrm{n})$ and weight average molecular weight $(M \mathrm{w})$ of $6,6-\mathrm{PI}$ were 24,000 and 88,000 , respectively. $M \mathrm{w}$ of PAA(PMDA/DADE) was 48,000 .

The imidization of PI was confirmed by IR (Fig. 1). There was no difference between the IR of the $150{ }^{\circ} \mathrm{C}$ and the $300{ }^{\circ} \mathrm{C}$ cured films from the absorptions at $1710 \mathrm{~cm}^{-1}$ (imide $\mathrm{C}=\mathrm{O}$ ) and at 1660 $\mathrm{cm}^{-1}$ (secondary amide). From the IR results, it was confirmed that imidization was completed at least by the drying condition at $150{ }^{\circ} \mathrm{C}$.

\subsection{Thermal and mechanical properties of PIs}

The 6,6-PI solution was cast on a glass plate, dried in an air oven at $150{ }^{\circ} \mathrm{C}$ and $300{ }^{\circ} \mathrm{C}$ for $1 \mathrm{~h}$, respectively. The tensile properties of 6,6-PI film were compared with those of the PI(PMDA/DADE) film. Figure 2 shows the tensile tests of the PI films in the form of stress-strain curves and the results are summarized in Table 1. PI(PMDA/DADE) after curing at $300{ }^{\circ} \mathrm{C}$ showed tensile modulus $(E)$ at 2.23 $\mathrm{GPa}$, tensile strength $\left(\sigma_{\mathrm{b}}\right)$ at $160 \mathrm{MPa}$, and elongation at break $\left(\varepsilon_{\mathrm{b}}\right)$ at $88 \%$. 6,6-PI after heating at $300{ }^{\circ} \mathrm{C}$ showed similar tensile properties; tensile modulus at $2.68 \mathrm{GPa}$, tensile strength at $160 \mathrm{MPa}$ and elongation at break at $86 \%$.

From the viscoelastic measurements, the glass transition temperature $\left(T_{\mathrm{g}}\right)$ of the 6,6-PI was found to be even higher than that of PI(PMDA/DADE) (Fig. 3). The storage modulus $\left(E^{\prime}\right)$ value of the 6,6-PI was also higher than that of PI(PMDA/DADE).

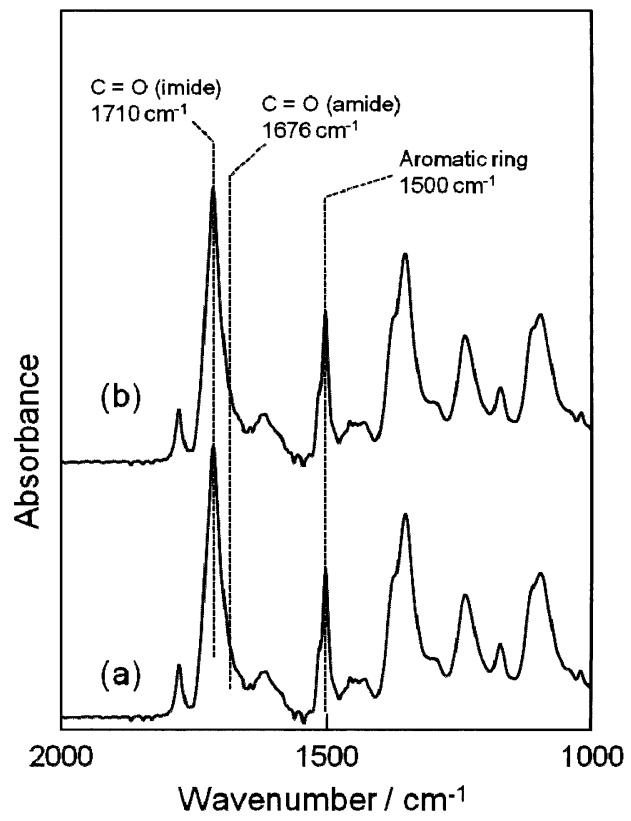

Figure 1. IR spectra of 6,6-PI after drying at $150{ }^{\circ} \mathrm{C}$ (a), and at $300^{\circ} \mathrm{C}(\mathrm{b})$.

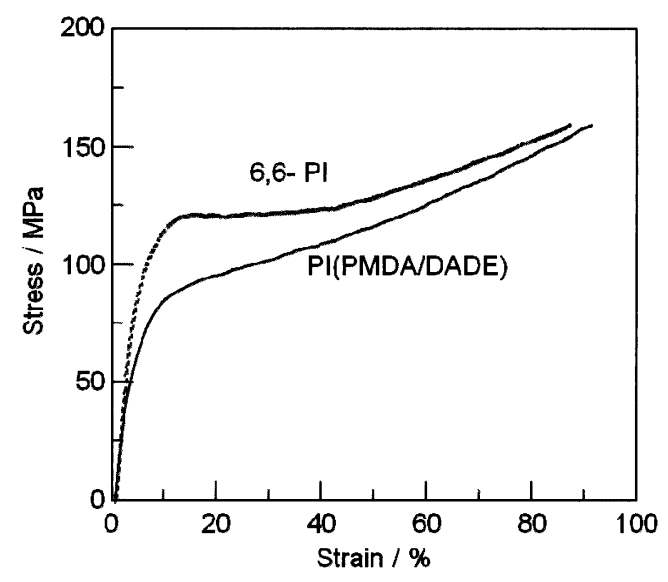

Fig. 2. Stress-strain curves of 6,6-PI film and PI(PMDA/DADE) film. 
J. Photopolym. Sci. Technol., Vol.24, No.3, 2011

Table 1. Mechanical and Thermal properties of PIs.

\begin{tabular}{|c|c|c|c|c|c|c|}
\hline & \multicolumn{3}{|c|}{ Mechanical properties } & \multicolumn{3}{|c|}{ Thermal properties } \\
\hline & $\begin{array}{c}E \\
(\mathrm{GPa})\end{array}$ & $\begin{array}{c}\sigma_{\mathrm{b}} \\
(\mathrm{MPa})\end{array}$ & $\begin{array}{c}\varepsilon_{\mathrm{b}} \\
(\%)\end{array}$ & $\begin{array}{l}T_{\mathrm{d} 5} \\
\left({ }^{\circ} \mathrm{C}\right)\end{array}$ & $\begin{array}{l}T_{\mathrm{d} 10} \\
\left({ }^{\circ} \mathrm{C}\right)\end{array}$ & $\begin{array}{r}T_{\mathrm{g}} \\
\left({ }^{\circ} \mathrm{C}\right)\end{array}$ \\
\hline 6,6-PI & 2.68 & 160 & 86 & 532 & 556 & 427 \\
\hline PI(PMDA/DADE) & 2.23 & 160 & 88 & 562 & 578 & 417 \\
\hline
\end{tabular}

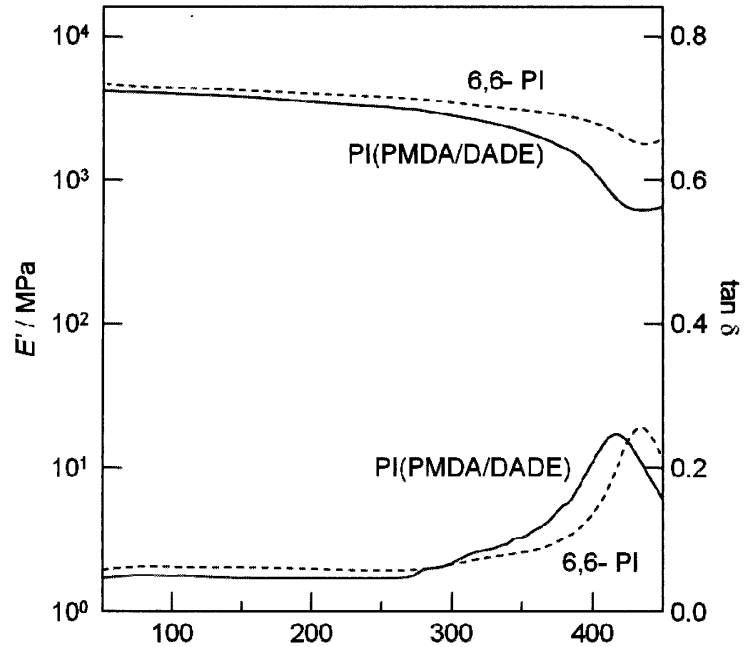

Fig. 3. Viscoelastic analyses of 6,6-PI film and PI(PMDA/DADE) film.

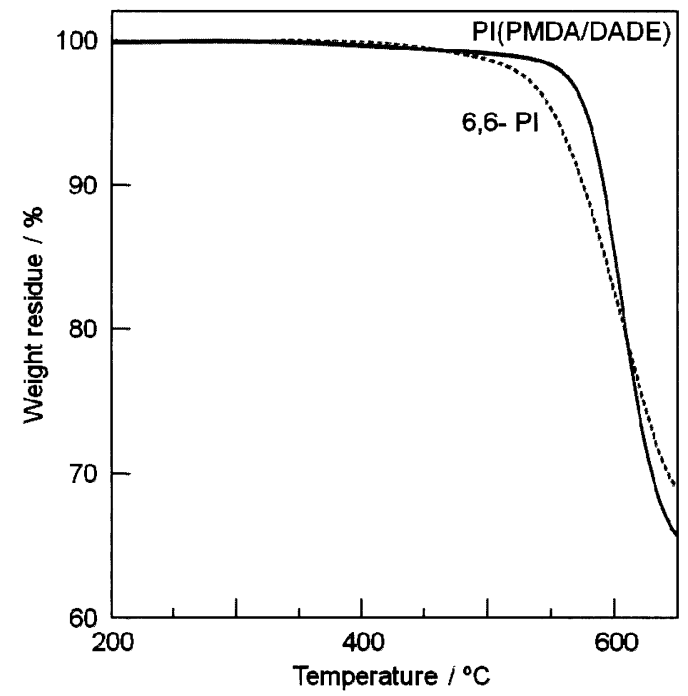

Fig. 4. TGA thermograms of 6,6-PI and $\mathrm{PI}(\mathrm{PMDA} / \mathrm{DADE})$ under argon at a heating rate of $5{ }^{\circ} \mathrm{C} / \mathrm{min}$
Thermal stability of the 6,6-PI and PI(PMDA/DADE) was examined by TGA (Fig. 4 and Table 1). The $5 \%$ and $10 \%$ weight loss temperatures $\left(T_{5}\right.$ and $\left.T_{10}\right)$ of 6,6-PI was lower than those of PI(PMDA/DADE). The methyl group of DAT in 6,6-PI may be the reason for the low thermal stability.

\section{Conclusions}

We successfully prepared soluble and highly heat resistant 6,6-PI using the new three step reaction to control the sequence of the monomers. The mechanical properties of the 6,6-PI film were as high as those of the PI(PMDA/DADE) film. Thermal properties were also excellent with high $T_{\mathrm{g}}$, though initial weight loss was slightly larger than PI(PMDA/DADE) because of the methyl group. 6,6-PI also has other advantages as follows. 6,6-PI can be prepared even in the presence of small amount of water, the vanish is stable and preserved at the ambient atmosphere, and films can be processed using the stable imidized form in a short time.

\section{References}

[1] M. Nandi, J. A. Conklin, L. Salvati, A. Sen, Chem. Mater, 3 (1991) 201.

[2] H. H. Huang, B. Orier, G. L. Wilker, Macromolecules, 20 (1987) 1322.

[3] D. Soane, Z. Martynenko, "Polymers in Microelectronics: Fundamentals and Applications", Elsevier, Amsterdam (1989).

[4] M. K. Gohsh, K. L. Mital , "Polyimides: Fundamentals and Applications", Marcel Dekker, New York (1996).

[5] H. Itatani U. S. Patent 5,502,143 (1996). 